\title{
Feasibility of Using ${ }^{36} \mathrm{Cl}$ to Depict Water Infiltration at the Pit 7 Complex, LLNL Site $\mathbf{3 0 0}$
}

\author{
G.J. Nimz
}

January 25, 2002

Lawrence

Livermore

National

Laboratory

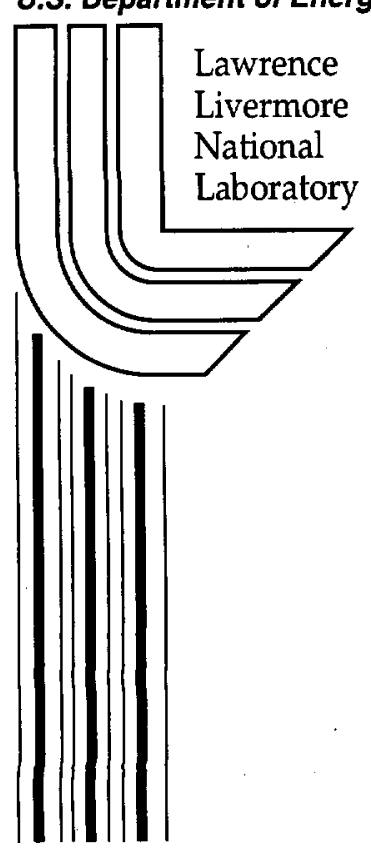




\section{DISCLAIMER}

This document was prepared as an account of work sponsored by an agency of the United States Government. Neither the United States Government nor the University of California nor any of their employees, makes any warranty, express or implied, or assumes any legal liability or responsibility for the accuracy, completeness, or usefulness of any information, apparatus, product, or process disclosed, or represents that its use would not infringe privately owned rights. Reference herein to any specific commercial product, process, or service by trade name, trademark, manufacturer, or otherwise, does not necessarily constitute or imply its endorsement, recommendation, or favoring by the United States Government or the University of California. The views and opinions of authors expressed herein do not necessarily state or reflect those of the United States Government or the University of California, and shall not be used for advertising or product endorsement purposes.

This work was performed under the auspices of the U. S. Department of Energy by the University of California, Lawrence Livermore National Laboratory under Contract No. W-7405-Eng-48.

This report has been reproduced directly from the best available copy.

Available electronically at http://www.doe.gov/bridge

Available for a processing fee to U.S. Department of Energy and its contractors in paper from

U.S. Department of Energy

Office of Scientific and Technical Information

P.O. Box 62

Oak Ridge, TN 37831-0062

Telephone: (865) 576-8401

Facsimile: (865) 576-5728

E-mail: reports@adonis.osti.gov

Available for the sale to the public from

U.S. Department of Commerce

National Technical Information Service

5285 Port Royal Road

Springfield, VA 22161

Telephone: (800) 553-6847

Facsimile: (703) 605-6900

E-mail: orders@ntis.fedworld.gov

Online ordering: http://www.ntis.gov/ordering.htm

OR

Lawrence Livermore National Laboratory

Technical Information Department's Digital Library

http://www.llnl.gov/tid/Library.html 


\title{
LLNL LDRD Final Project Report Project 01-FS-009
}

\section{Feasibility of Using ${ }^{36} \mathrm{Cl}$ to Depict Water Infiltration at the Pit 7 Complex, LLNL Site 300}

Gregory J. Nimz

Geosciences and Environmental Technologies Division

Earth and Environment Directorate

\begin{abstract}
Measurements of bomb-pulse ${ }^{36} \mathrm{Cl}$ and chloride concentrations in soils from the Pit 7 Complex basin, LLNL Site 300, combined with a demonstration model of moisture flux and infiltration rate, indicate that the bomb-pulse can be an extremely useful tool for the characterization of the unsaturated hydrology at Site 300 . Bomb-pulse ${ }^{36} \mathrm{Cl}$ is readily identifiable in the soil column, and exhibits moisture infiltration-related variations at different locations. It can be used to calibrate chloride accumulation models of unsaturated flow. In the continuing investigation of the origin and development of the Pit 7 Complex tritium plume, bomb-pulse ${ }^{36} \mathrm{Cl}$ will provide a useful mechanism for hydrologic characterization.
\end{abstract}

\section{Purpose of Project}

The purpose of this feasibility study was to determine if variation in fallout ${ }^{36} \mathrm{Cl}$ abundance in soil profiles within the LLNL Site 300 Pit 7 Complex are of sufficient magnitude that chlorine and ${ }^{36} \mathrm{Cl}$ can be used to determine the sources of ground water invading the Complex. Because of the semi-arid unsaturated character of the soils surrounding the Pit 7 Complex, physical measurements indicative of moisture movement and flux are prone to high degrees of uncertainty. In situations like this, chemical methods have proven more useful than physical methods (Allison et al., 1994).

The Pit 7 Complex is a series of landfill pits in the northwest corner of Site 300 which contain waste debris from firing table tests conducted from the late 1950's to 1988. The pits were closed and covered, but today are responsible for a groundwater contaminant tritium plume. The source(s) of the invading ground water is unclear. Some of the water probably comes from an underlying aquifer that has risen to the depths of the pits in recent wet El Niño years. But water also may enter the pits from surface runoff or flow through the alluvial soils on the hillslopes surrounding the pits. The tritium then enters into the bedrock aquifer, creating in effect two tritium plumes - one migrating downvalley (southeast) through saturated alluvium, and one migrating downdip (east-northeast) in bedrock. It is possible that an engineering solution could prevent the alluvium at the pits from becoming saturated and thereby prevent further tritium release. In order to assess this possibility the sources of water in the alluvium and bedrock, the rate of migration of water in these units, and the degree and nature of their connectivity must be determined.

Chlorine-36 derived from atmospheric nuclear testing in the 1950-1960's (fallout) can be used as a tracer to detect groundwater entering the system during that period. This includes water already at the water table as well as soil-water currently infiltrating toward the water table. The measurements provide a means of distinguishing areas of high and low infiltration, and in 
unsaturated media indicate the depth of soilwater infiltration since the 1950-1960's (thus providing a recharge rate). This provides an indication of the degree to which water flows overland as opposed to infiltrating. Chlorine- 36 in soil profiles on a hillslope can indicate the

relative volumes of water that flow through the slope. Previous reconnaissance measurements of ${ }^{36} \mathrm{Cl}$ in Pit 7 area ground waters indicated that fallout ${ }^{36} \mathrm{Cl}$ was still present in the soil column.

\section{Project Design/Activities}

This project made use of soil cores from Site 300 collected by the LLNL Environmental Protection Department during late FY 2001. The core was segmented and chloride was extracted from each segment. The ratio of ${ }^{36} \mathrm{Cl}$ to total chloride was measured in each extract by accelerator mass spectrometry at the LLNL CAMS facility. In this way a depth profile of ${ }^{36} \mathrm{Cl} / \mathrm{Cl}$ was determined throughout the soil column at the locations of these drill cores.

Soil Cores. The soil drill cores were collected during drilling of a series of piezometer test holes on the western slope of the basin contain the Pit 7 Complex. In all, sixteen holes were drilled, several of which extended into the underlying bedrock. The holes were arranged in four groups, with the holes belonging to each group in close proximity. Thus, if core recovery through a particular depth interval was insufficient or lacking in one core, soil from an adjacent core within the same group could be substituted in order to achieve a complete profile. This provided significantly better coverage than is commonly achieved.

Cores were collected from all four piezometer groups, one being archived for future use external to this LDRD project. Three cores were prepared for ${ }^{36} \mathrm{Cl}$ analysis. The cores extended from ground surface to depths of 7.3, 7.6, and 7.9 meters - the depths to competent bedrock in the respective holes. The cores were divided into approximately $25 \mathrm{~cm}$ (12 inch) intervals, and split in half lengthwise. Only one of the lengthwise halves was removed for this project - the other half was left in the original core boxes in the EPD storage facility for other uses. Each 25 $\mathrm{cm}$ sample interval was disaggregated and placed into new heavy-gauge plastic sample bags. This then becomes the limit to our resolution of the ${ }^{36} \mathrm{Cl} / \mathrm{Cl}$ profile.

The cores demonstrated that the soils within the Pit 7 basin are highly stratified, with large variability in texture and mineralogy. Cementation by carbonate occurred in short ( $<2$ meter) near-surface intervals in all cores. While it was beyond the scope of this project to identify and document soil textures, mineralogy, and stratigraphy, some of this information has been recorded by EPD personnel and exists in their records. In addition, aliquots of each samples processed during this project have been archived for possible future soil characterization work. Every core was carefully photographed prior to sample removal, and these are available from the EPD.

Chloride Leachates Solutions. After complete disaggregation of the soil sample, 100-200 grams were placed in a $250 \mathrm{ml}$ HDPE bottle along with $175-300 \mathrm{mls}$ of deionized (DI) water. The water was previously analyzed for stable chloride and ${ }^{36} \mathrm{Cl}$ concentration to insure that insignificant amounts of either were being incorporated into the analysis. The samples were initially shaken by hand to mix the soil and water, and then placed on a commercial shaker table at $300 \mathrm{rpm}$ for 2 hours. The bottles were then centrifuged at $4000 \mathrm{rpm}$ for 15 minutes and the supernate leachate was poured into a new $250 \mathrm{ml} \mathrm{HDPE}$ bottle. Liquid recovery was generally about $60 \%$ (i.e., the final leachate represents about $60 \%$ of the DI water initially added). An additional $120 \mathrm{mls}$ of DI water was then added to the centrifuged soil, the samples were initially shaken by hand to mix the soil and water, and then shaken on the shaker table ( $300 \mathrm{rpm})$ for an 
additional 2 hours. After again centrifuging ( $4000 \mathrm{rpm}, 15$ minutes), the supernate leachate was poured into a new $250 \mathrm{ml}$ HDPE bottle.

Electrostatic attraction between water molecules and fine particles, presumably mostly clays, kept a significant amount of material in suspension after centrifugation. To flocculate this material, one drop of concentrated $\mathrm{HNO}_{3}$ was added to the leachate after removal from the soil mass, and the leachate centrifuged for 5 minutes at $4000 \mathrm{rpm}$. The additional protons in solution effectively lessening the particle-water attraction, thus allowing the particles to settle during centrifugation.

All samples were then filtered to $0.45 \mu \mathrm{m}$ using commercially-available filters. Each of the leachates in the two-step leaching process was analyzed for chloride concentration by ion chromatography. Chloride concentrations were measured in each separately leachate in order to monitor the leaching process. As would be expected, most of the leachable chloride was contained in the first leach. As a test, selected samples were leached for a third time by the same process; negligible chloride was found in the third leachates.

For each sample, the two leachates (first and second) were combined for the ${ }^{36} \mathrm{Cl} / \mathrm{Cl}$ analysis.

${ }^{36} \mathrm{Cl}$ Analyses. Chloride was extracted from the leachate solutions using the standard $\mathrm{AgCl}$ precipitation technique developed at the CAMS facility. $\mathrm{AgCl}$ yields were consistently low relative to the amounts of chloride present in the leachates. This suggests there were components present in the leachate solutions that would either interfere with the usual Ag-Cl solubility function, complex with chloride in basic solutions $(\mathrm{pH}>>7)$ permitting removal of chlorine by filtration (to $0.45 \mu \mathrm{m}$ ) during the chemical extraction procedure, or facilitate the removal of $\mathrm{AgCl}$ through water-washing during the chemical extraction procedure.

The analysis of ${ }^{36} \mathrm{Cl} / \mathrm{Cl}$ was conducted at the LLNL Center for Accelerator Mass Spectrometry. Between 0.5 and $3.0 \mathrm{mg} \mathrm{AgCl}$ were loaded into a AgBr-packed target for analysis. Generally, between 3 and $5 \mathrm{mg} \mathrm{AgCl}$ are used for AMS analysis, but the lower chemical yields did not permit this. Nonetheless, ${ }^{37} \mathrm{Cl}$ (stable isotope) currents were consistently above $3 \mu \mathrm{A}$, which is more than sufficient for high quality AMS analysis.

\section{Results}

This study was asking the singular question whether it would be feasible to use ${ }^{36} \mathrm{Cl} / \mathrm{Cl}$ profiles within the Site 300 Pit 7 Complex basin to delineate areas of high versus low moisture infiltration. The results indicate that it is feasible because the bomb-pulse peak: 1) is identifiable in Pit 7 Complex soil core profiles, 2) varies in magnitude at different location (indicating variable moisture volumes), 3) occurs apparently at varying depths at different locations (indicating variable moisture flow rates), and 4) show internal "structure" within single profiles that likely can be correlated with soil stratigraphy, texture, or moisture content (providing finerscale hydrologic detail that would be suitable for numerical model input).

${ }^{36} \mathrm{Cl}$ Profiles. Figure 1 compares ${ }^{36} \mathrm{Cl} / \mathrm{Cl}$ bomb-pulse profiles from cores $1717 / 1718$ and $1720 / 1721$. The profiles are derived by subtracting the background, natural, ${ }^{36} \mathrm{Cl}$ from the measured values. Background is derived from the measured soil chloride concentrations and regional modern non-bomb-pulse ${ }^{36} \mathrm{Cl} / \mathrm{Cl}$ ratio of $150 \mathrm{E}-15$, which has been determined in previous studies (Nimz, 1998). All values in Figure 1 therefore represent atoms of bomb-pulse ${ }^{36} \mathrm{Cl}$. The most striking feature is the much larger magnitude of bomb-pulse in profile $1717 / 1718$. 
Not only is the peak maximum larger than in $1720 / 1721$, but the integrated ${ }^{36} \mathrm{Cl}$ atom total is also much larger. This would suggest that infiltration amounts have been much greater at the location of $1720 / 1721$ than at $1717 / 1718$ during the past 45 years.

The depth of the bomb-pulse peak maximum also appears to be greater for 1720/1721 than $1717 / 1718$; by approximately 1.2 meters. The differences in depth for the centers of ${ }^{36} \mathrm{Cl}$ mass for the two profiles appear to be even greater. The greater depth is consistent with larger infiltration at the location of $1720 / 1721$, as perhaps is the greater dispersion of the peak at the $1717 / 1718$ location. The dispersion may, however, be due to local soil characteristics which were not examined in this study.

In addition to the differences in dispersion, both profiles show evidence of a smaller, "trailing" ${ }^{36} \mathrm{Cl}$ peak at depths shallower than the peak maximum (by $\sim 2.5$ meters in each case). These "structural" features within the profiles may be indicative of local variations in hydrologic parameters within the Pit 7 Complex soils.

It is interesting to note that both profiles show a very large amount of bomb-pulse ${ }^{36} \mathrm{Cl}$ within the top 1-1.5 meters. There is no recent source for this ${ }^{36} \mathrm{Cl}$. It appears that bomb-pulse ${ }^{36} \mathrm{Cl}$ from the 1950 's may be bound up and recycling in the grassy vegetation within the basin. A similar vegetation-related recycling of the bomb-pulse has been observed in eastern Canada and elsewhere (Cornett et al., 1997).

Chlorine Profiles. Figure 2 compares soil chloride concentration profiles from cores $1717 / 1718$ and 1720/1721. Although chloride concentrations are low in both profiles, $1717 / 1718$ are nearly twice $1720 / 1721$ values in the interval 3-5 meters. This is consistent with greater infiltration flux at the location of $1720 / 1721$, as was inferred from the ${ }^{36} \mathrm{Cl}$ profiles. Both profiles show a zone f greater chloride at a depth of about 1 meter. This may be a transient effect of evaporation of near-surface water. The very large increase in chloride at the bottom of the $1720 / 1721$ profile (>7 meters) may be a zone of accumulation of chloride as has been observed elsewhere (e.g., Tyler et al., 1996). More likely, it reflects the fact that the soil at this depth is not alluvium/colluvium, but rather is weathered bedrock. The in-situ contribution of chloride from altered (weathered) crystalline material is consistent with the much lower ${ }^{36} \mathrm{Cl}$ values observed at this depth (Figure 1).

Moisture Velocity and Flux Model. Because this was only a feasibility study, it was not within the scope or budget to collect data on a number of characteristics of the Pit 7 basin soils that one would need to derive models of moisture infiltration based on chloride content or bombpulse ${ }^{36} \mathrm{Cl}$ profiles (e.g., soil moisture contents, soil particle size distribution, soil mineralogy). However, by using observed background (i.e., non-bomb-pulse) precipitation ${ }^{36} \mathrm{Cl} / \mathrm{Cl}$ values, estimations of background ${ }^{36} \mathrm{Cl}$ flux rates to the Earth's surface (guided by Bentley et al., 1986 and Phillips, 2001), and by assuming soil moisture contents, averaged model moisture fluxes and soil water infiltration velocities can be derived for the soil profiles (Phillips et al., 1988; Scanlon, 1992). It must be emphasized here that this exercise is for illustrative purposes only; it is highly model dependent. In particular, the model assumes piston-like moisture flow and closelyuniform soil texture/mineralogy. Nonetheless, the model provides a fairly good first approximation for moisture flux in unsaturated soils (cf. Scanlon, 1992).

The model, which we calibrate using the ${ }^{36} \mathrm{Cl}$ bomb-pulse, uses the following relation for soil moisture flux $\left(\mathrm{q}_{\mathrm{w}}\right)$ : 


$$
q_{w}=(J S)\left(C l_{s w}\right)^{-1}
$$

where: $\underline{\mathrm{JS}}$ is the annual flux of chloride to the Earth's surface $\left(\mathrm{g}\left(\mathrm{m}^{-2}\right) \mathrm{yr}^{-1}\right)$ and $\underline{\mathrm{Cl}}_{\underline{\mathrm{w}}}$ is the concentration of chloride in soil pore water. Under the assumption that all of the leachable chloride in the soils occurs in solution within the soil pore water, $\mathrm{Cl}_{\text {sw }}$ can be derived from the measured soil chloride concentrations (derived from the leachate solutions) by the following relation:

$$
\mathrm{Cl}_{\mathrm{sw}}=\mathrm{Cl}_{\mathrm{s}} \mathrm{W}_{\mathrm{m}}^{-1}
$$

where: $\underline{\mathrm{Cl}}_{\underline{s}}$ is the measured concentration of chloride in the soils and $\underline{\mathrm{W}}_{\underline{m}}$ is the mass fraction of water within the soils. The latter is related to the volumetric soil moisture content $(\theta)$ by the following:

$$
\mathrm{W}_{\mathrm{m}}=\theta \rho_{\mathrm{w}} \rho_{\mathrm{s}}^{-1}
$$

where: $\varrho_{w}$ is soil water density and $\varrho_{s}$ is the bulk soil density. For the present demonstration, $\theta$ values are being estimated.

The time it has taken the chloride to accumulate to any depth within a soil column $\left(T_{d}\right)$ can be estimated by the following relation:

$$
\mathrm{T}_{\mathrm{d}}=\Sigma \mathrm{Cl}_{\mathrm{d}}\left(\mathrm{Js}^{-1}\right)
$$

Where $\Sigma \mathrm{Cl}_{\mathrm{d}}$ is the sum of the chloride within the soil column down to depth $\mathrm{d}$. This relation between accumulation time and chloride flux (Js) permits the calibration of this model using bomb-pulse ${ }^{36} \mathrm{Cl}$. The peak in atmospheric nuclear testing producing the ${ }^{36} \mathrm{Cl}$ bomb-pulse was in 1956, 45 years before the Pit 7 basin soil cores were collected. Therefore it could have taken no more than 45 years for the bomb-pulse peak to reach its observed depth. Under the assumptions of this model, it could have then taken no more than 45 years for the chloride in the soil column above the bomb-pulse peak to accumulate. The value of Js is then determined by the relation:

$$
J_{s}=\sum C l_{d}\left(T_{d}^{-1}\right) \quad \text { where } T_{d}=45 \text { years }
$$

From this, a value of $0.53 \mathrm{~g}\left(\mathrm{~m}^{-2}\right) \mathrm{yr}^{-1}$ is derived for soil profile $1717 / 1718$, and a value of $0.54 \mathrm{~g}\left(\mathrm{~m}^{-2}\right) \mathrm{yr}^{-1}$ is derived for $1720 / 1721$. These values are in very close agreement, which is what should be expected for soils in such close proximity.

Because the relation between soil moisture content and moisture flux $\left(\mathrm{q}_{\mathrm{w}}\right)$ is linear in this model, we are able to derive the relative moisture fluxes throughout the profile for a uniform distribution of soil moisture. By using a moderate soil moisture value, $0.2 \mathrm{~m}^{3}$ water $/ \mathrm{m}^{3}$ soil, and bracketing that value by the likely range in soil moisture contents for Site $300( \pm 0.1$ $\mathrm{m}^{3}$ water $/ \mathrm{m}^{3}$ soil), a generalized picture can be gained concerning moisture flux within the Pit 7 basin.

Figures 3 and 4 show the moisture flux profiles for cores $1717 / 1718$ and $1720 / 1721$. For a given theta value, moisture flux at the location of $1720 / 1721$ is greater than at $1717 / 1718$. Within this model, this is a direct result of the greater chloride concentrations in $1717 / 1718$. However, the result is very consistent with the shallower maximum, greater dispersion, and greater total 
${ }^{36} \mathrm{Cl}$ mass observed in the $1717 / 1718$ bomb-pulse profile (Figure 1). Taken together, this appears to be strong evidence for greater infiltration at the location of $1720 / 1721$. Therefore it does appear feasible to use chlorine and bomb-pulse ${ }^{36} \mathrm{Cl}$ to indicate variations in infiltration throughout the Pit 7 Complex basin. The determination of this feasibility was the objective of this study.

Infiltration velocity (V) can be derived from moisture flux and volumetric soil moisture content:

$$
\mathrm{V}=\left(\mathrm{q}_{\mathrm{w}}\right)(\theta)^{-1}
$$

However, under the assumption that all leachable chloride occurs in solution within the soil pore water, $q_{w}$ becomes a direct function of $\theta$ (through rearrangement of equations (1), (2), and (3)), and $V$ therefore becomes independent of $\theta$. That is, by rearranging equations (1), (2), (3), and (6), the following relation is obtained (with appropriate conversion of units):

$$
\mathrm{V}=\mathrm{Js}\left(\mathrm{Cl}_{\mathrm{s}}^{-1}\right) \rho_{\mathrm{w}} \rho_{\mathrm{s}}-1
$$

This at first seems an odd result, that infiltration velocity is independent of soil moisture content. But this is a feature of the chloride accumulation model where moisture flux is gauged by the accumulated chloride to a given depth. When it is assumed that all of the accumulated chloride is contained within the soil pore water, the volume of that water present no longer matters. Further, this is completely in accord with unsaturated zone flow theory, in which hydraulic head potentials are not transmitted through a soil water mass due to the lack of connectivity. Moisture flux is not a primary function of moisture content; it is the pressure head, not the water content that describes the energy status of the system (Stephens, 1996). Infiltration velocities can be derived either from equation (6), having previously derived $\mathrm{q}_{\mathrm{w}}$ and $\theta$ values, or directly from equation (7).

Figures 5 and 6 show the infiltration velocity profiles for cores 1717/1718 and 1720/1721. At all depths, infiltration velocity is greater at the location of $1720 / 1721$ than at $1717 / 1718$. An interesting feature of both profiles is the increase in velocity mid-profile, at 3-4 meters depth. Moisture flux also increases in this interval (Figures 4 and 5), both features being a direct result in this model of the chloride concentration profiles. This may be reflective of a change in soil composition at this depth. Although not quantitatively measured in this study, soils above this depth were observed to contain more abundant amounts of secondary carbonate material - in some cases appearing to be true petrocalcic soils.

\section{Conclusion}

The objective of this study was to determine the feasibility of using chlorine and bombpulse ${ }^{36} \mathrm{Cl}$ to depict water infiltration within the Pit 7 Complex basin of LLNL Site 300 . As the modeling exercise presented here demonstrates, chlorine and ${ }^{36} \mathrm{Cl}$ can be useful tools at Site 300 . The bomb-pulse peak is clearly identifiable, it varies in magnitude and total mass at different locations, and is useful in calibrating chloride accumulation models. In the continuing investigation of the origin and development of the Pit 7 Complex tritium plume, bomb-pulse ${ }^{36} \mathrm{Cl}$ will provide a useful mechanism for hydrologic characterization. 


\section{References}

Allison, G.B. and Hughes, M.W. (1978) The use of environmental chloride and tritium to estimate total local recharge to an unconfined aquifer. Austr. J. Soil Res. 16, 181-195

Bentley, H.W., F.M. Phillips, and S.N. Davis (1986) Chlorine-36 in the terrestrial environment. In: Handbook of Environmental Isotope Geochemistry, Vol. 2 (P. Fritz and J.-Ch. Fontes, eds), pp. 427-480.

Cornett, R.J., Andrews, H.R., Chant, L.A., Davies, W.G., Greiner, B.F., Imahori, Y., Koslowsky, V.T., Kotzer, T., Milton, J.C.D., and Milton, G.M., 1997. Is ${ }^{36} \mathrm{Cl}$ from weapons test fallout still cycling in the atmosphere? Nucl. Instr. Meth. Phys. Res., B123:378-381.

Nimz G.J. (1998) Lithogenic and cosmogenic tracers in catchment hydrology. In Isotope Tracers in Catchment Hydrology (Kendall, C. and McDonnell, J.J., eds.). Amsterdam and New York: Elsevier, pp. 247-289.

Phillips, F.M., J.L. Mattick, T.A. Duval, D. Elmore, and P.W. Kubik (1988) Chlorine-36 and tritium from nuclear weapons fallout as tracers for long-term liquid and vapor movement in desert soils. Water Resour. Res. 24, 1877-1891.

Phillips, F.M. (2000) Chlorine-36. In Environmental Tracers in Subsurface Hydrology (Cook, P. and Herczeg, A.L., eds.). Boston/Dordrecht/London: Kluwer Academic Press, pp. 299348.

Scanlon, B.R. (1992) Evaluation of liquid and vapor water flow in desert soils based on chlorine 36 and tritium tracers and nonisothermal flow simulations. Water Resour. Res. 28, $285-$ 297.

Stephens, D.B. (1996) Vadose Zone Hydrology. CRC Press, Inc., Boca Raton, Florida.

Tyler, S.W., J. B. Chapman, S. Conrad, D. Hammermiester, D. Blout, J. Miller, M. Sully and J. Ginanni (1996) Soil Water Flux on the Nevada Test Site: Temporal and Spatial Variations over the Last 120,000 Years. Water Resources Research. 32: 1481-1499. 


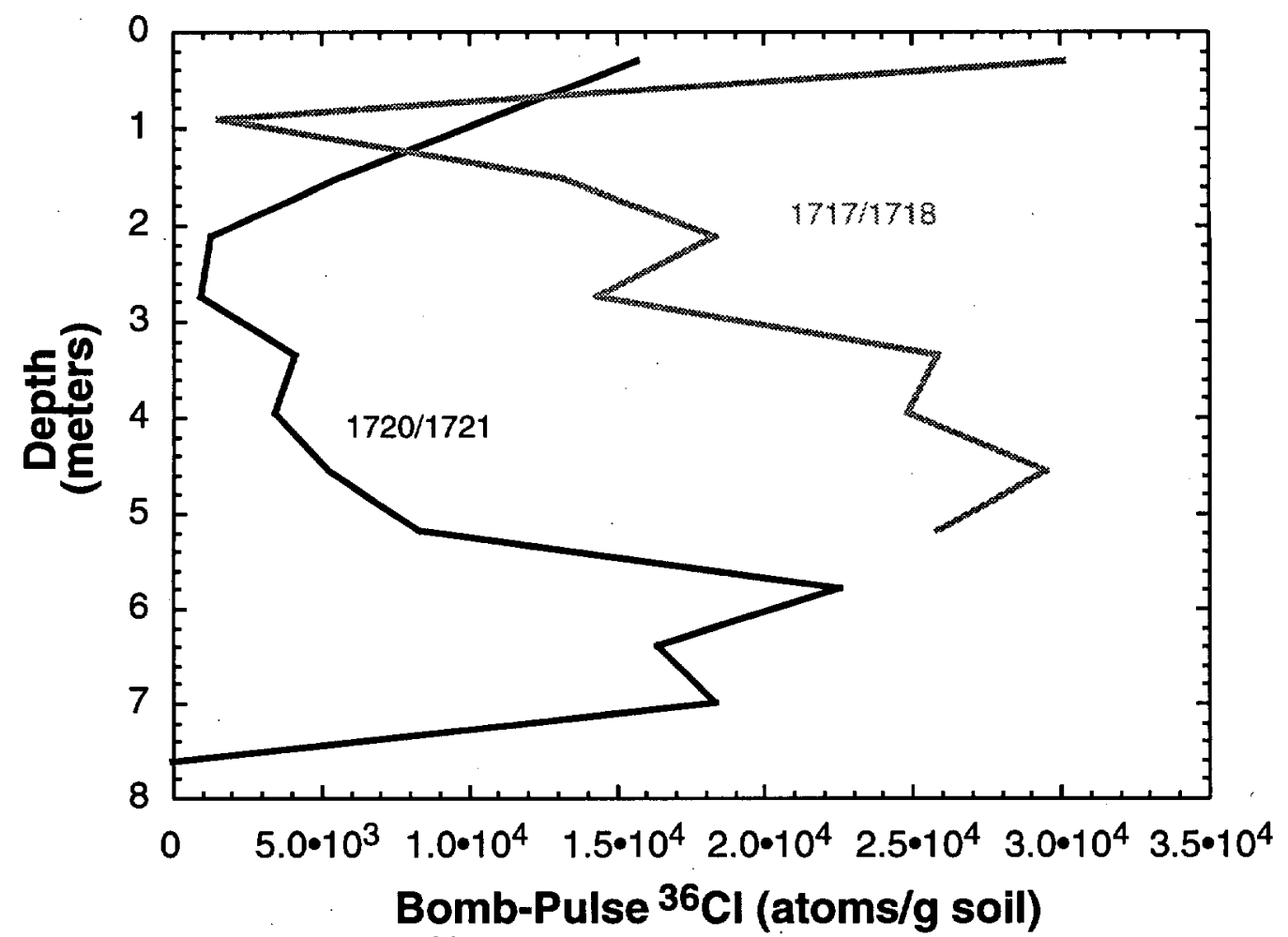

Figure 1. Bomb-pulse ${ }^{36} \mathrm{Cl}$ profiles from cores $1717 / 1718$ and 1720/1721. Background (non-bomb-pulse) ${ }^{36} \mathrm{Cl}$ atoms, based on soil $\mathrm{Cl}$ concentrations and the background precipitation ${ }^{36} \mathrm{C} / / \mathrm{Cl}$ ratio of $150 \cdot 10^{-15}$, have been subtracted.

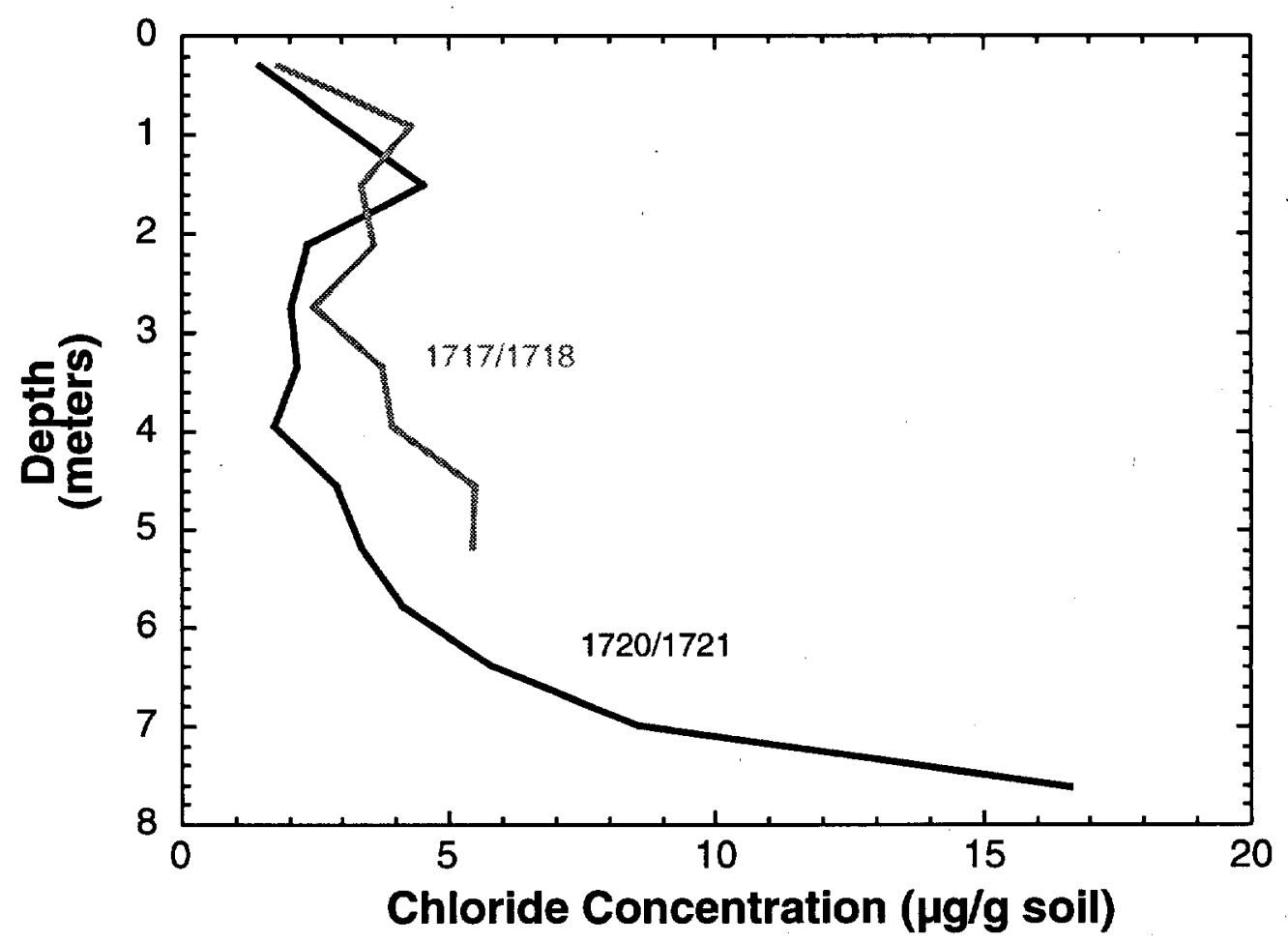

Figure 2. Soil chloride concentrations from cores $1717 / 1718$ and 1720/1721. Values calculated from leachate solution $\mathrm{Cl}$ concentrations, leachate volumes, and mass of leached soil at each interval. 


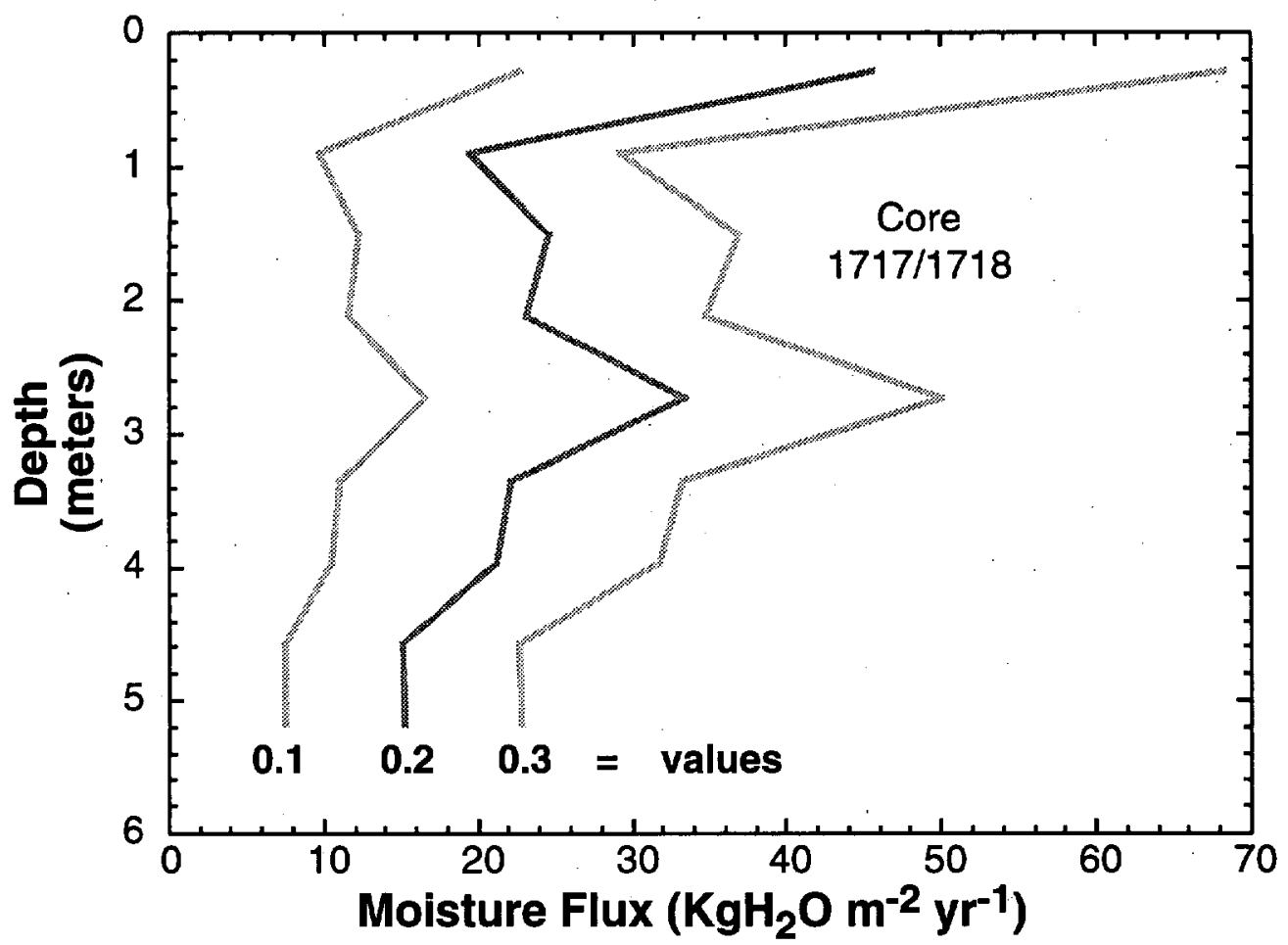

Figure 3. Calculated moisture flux at the location of core 1717/1718. Soil moisture contents (, $\mathrm{m}^{3}$ water $/ \mathrm{m}^{3}$ soil) shown span the range of probable values for these semi-arid soils. Actual values therefore probably lie within the two lighter shaded flux profiles (for 0.1 and 0.3 ).

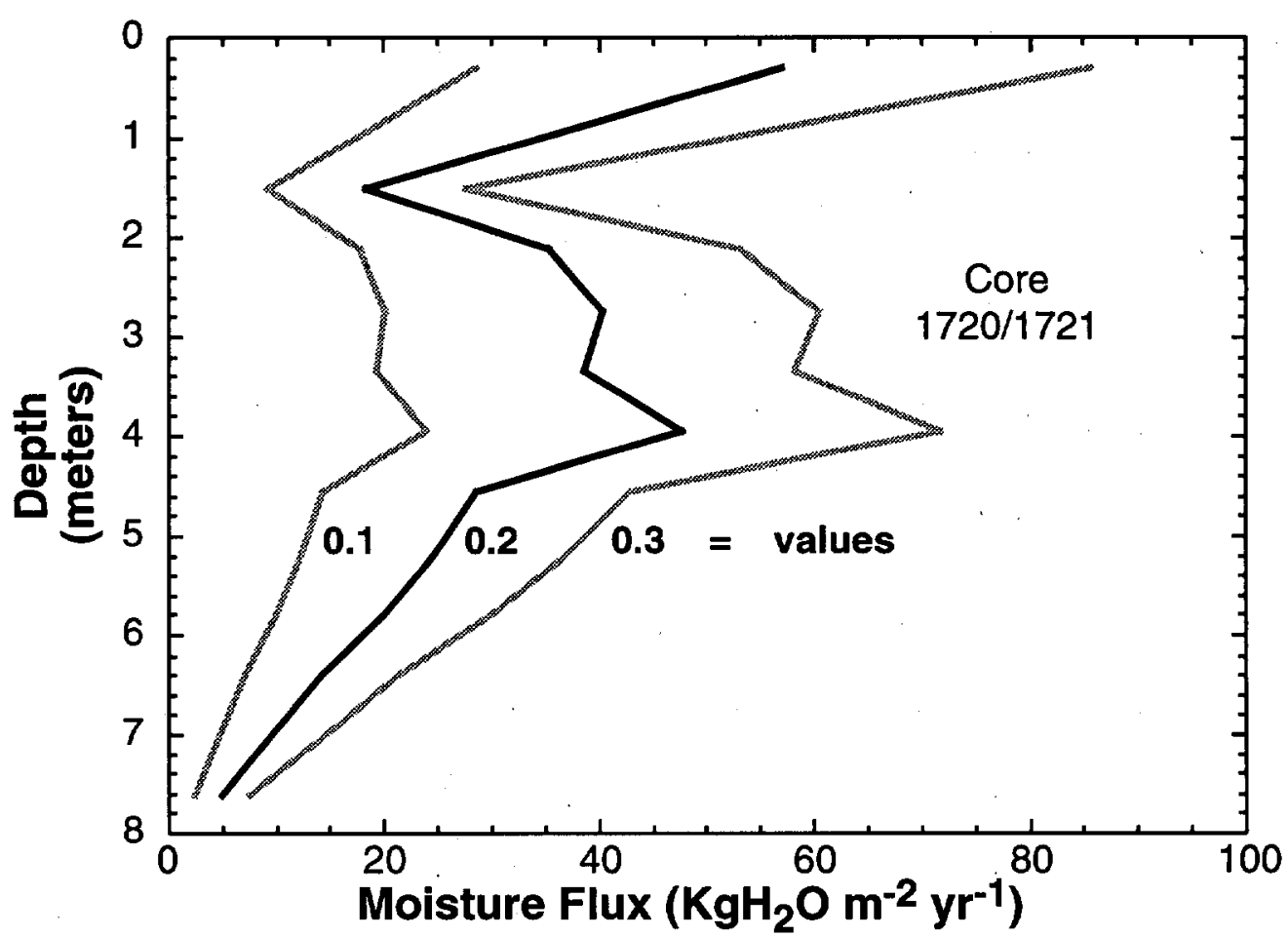

Figure 4. Calculated moisture flux at the location of core 1720/1721. Soil moisture contents $\left(, \mathrm{m}^{3}\right.$ water $/ \mathrm{m}^{3}$ soil) shown span the range of probable values for these semi-arid soils. Actual values therefore probably lie within the two lighter shaded flux profiles (for 0.1 and 0.3 ). 


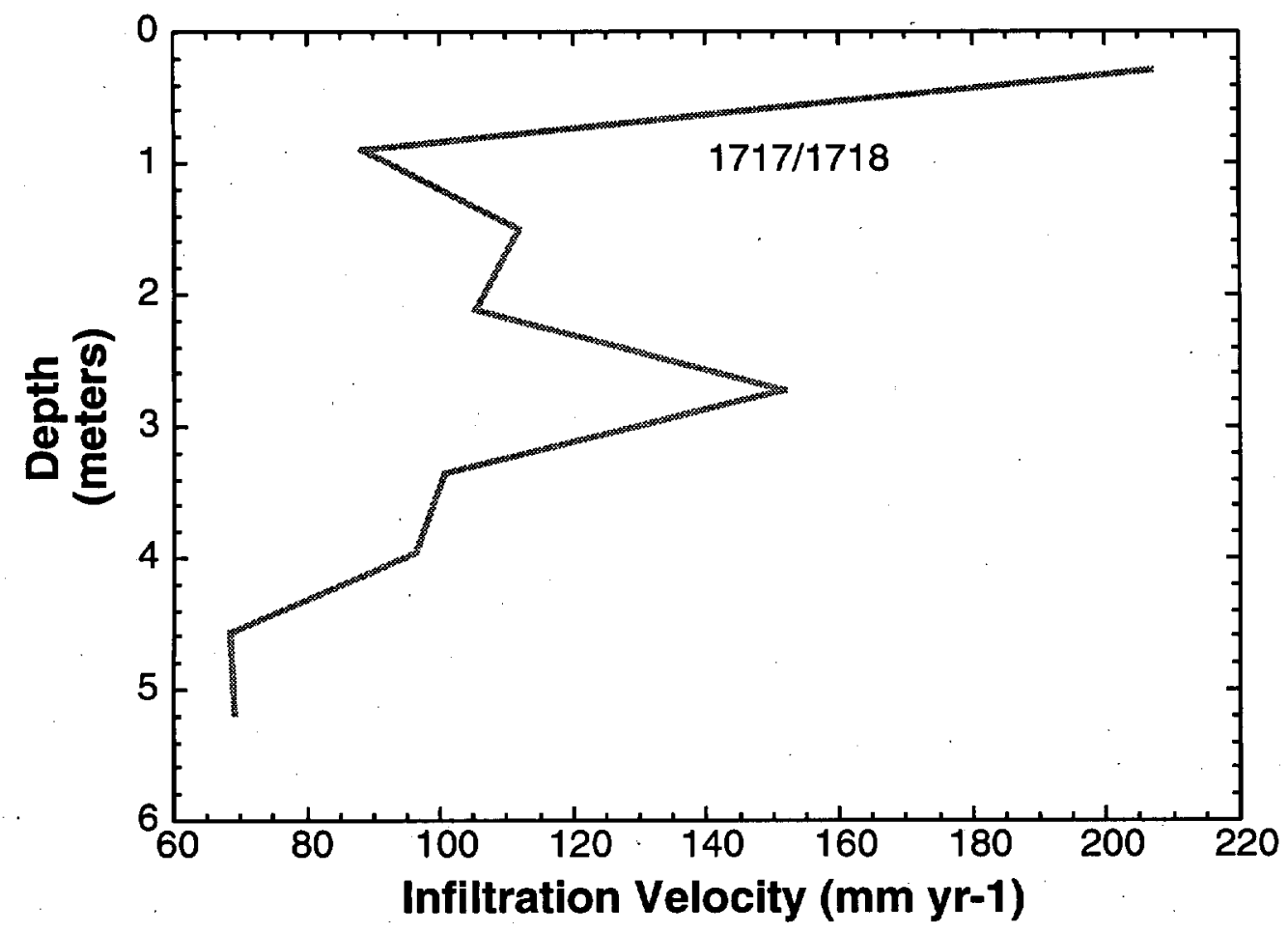

Figure 5. Calculated infiltration velocity at the location of core $1717 / 1718$. This profile is independent of the assumed moisture content values ( ), and is therefore a valid model realization of the chlorine accumulation model.

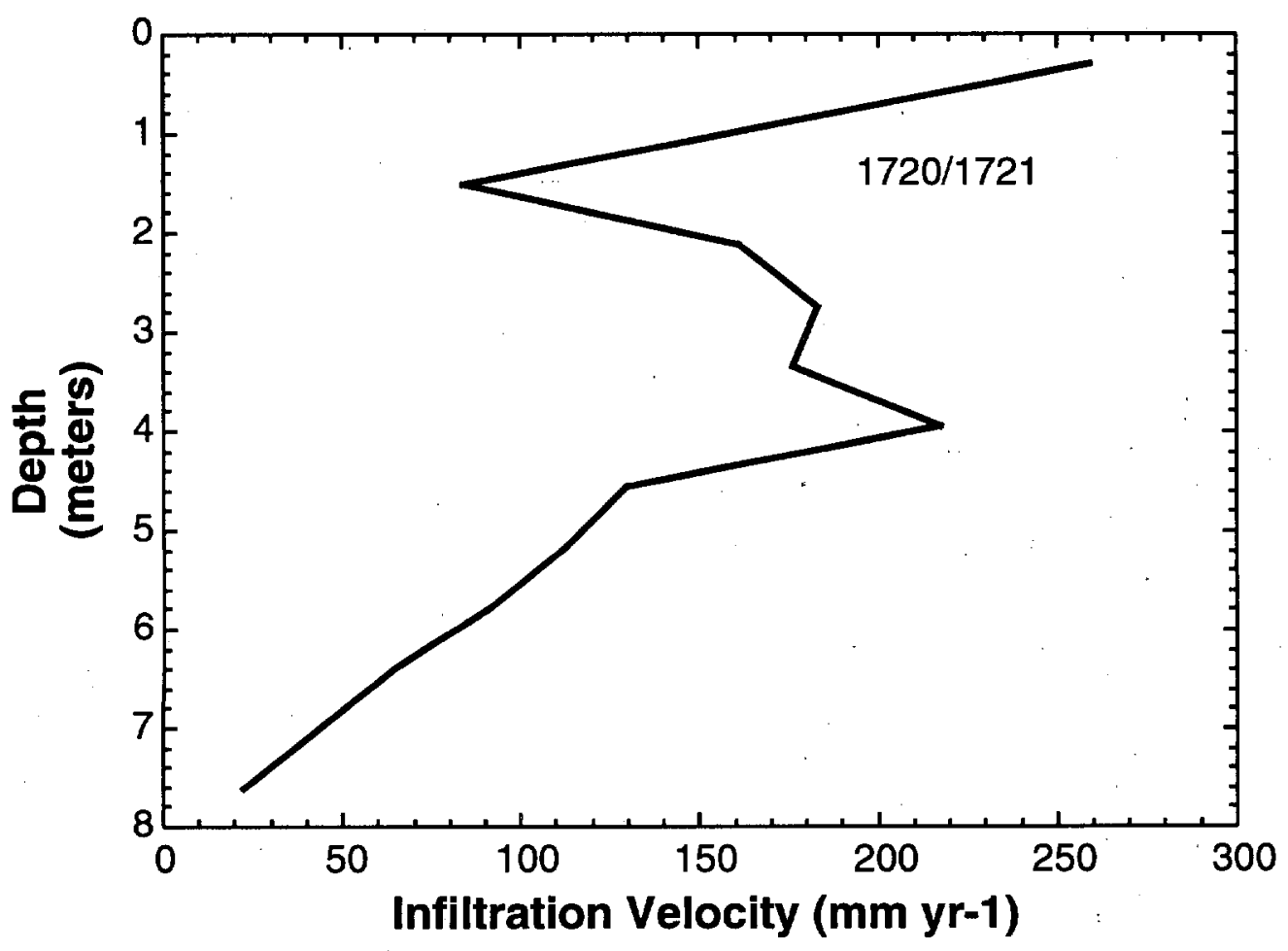

Figure 6. Calculated infiltration velocity at the location of core 1720/21. This profile is independent of the assumed moisture content values ( ), and is therefore a valid model realization of the chlorine accumulation model. 